\title{
Comparison of Burden of Caregiving among Different Levels of Amputation in Selected Hospitals in South- West Nigeria
}

\author{
Ojoawo AO*, Abdulfattah RI and Olaoye OA \\ Department of Medical Rehabilitation, Faculty of Basic \\ Medical Sciences, College of Health Sciences, Obafemi \\ Awolowo University, Nigeria \\ *Correspondling author: Ojoawo Adesola O, \\ Department of Medical Rehabilitation, Faculty of Basic \\ Medical Sciences, College of Health Sciences, Obafemi \\ Awolowo University, Nigeria
}

Received: September 12, 2017; Accepted: October 05, 2017; Published: October 12, 2017

\begin{abstract}
The task of caring for a relative with amputation might be somewhat daunting for the caregiver. This study compared the burden of caregiving among informal caregivers of individuals with different levels of amputation in selected hospitals in south western Nigeria.
\end{abstract}

The cross sectional survey involved 66 individuals with amputation and their caregivers. Zarit Burden Interview was used to assess the caregiver burden. Data were analysed using descriptive and inferential statistics. Alpha level was set at 0.05 .

The mean caregivers burden (55.6) of the amputees in this study was a little more than average but significantly $(t=2.842 p<0.05)$ higher for females $(59.44 \pm 10.53)$ than for males $(54.25 \pm 9.27)$. There was significant difference $(F=4.80, p<0.05)$ in caregiver burden among different levels of amputation with above knee being the highest $(63.43 \pm 9.51)$ and below knee $(52.38 \pm 8.29)$ been the lowest.

It can be concluded from the study that mean burden care, given to an average amputee may be estimate as just above average but above knee and female amputee may require more care.

\section{Introduction}

All over the world, 200 to 500 million major amputations are performed each year and approximately, 70,000 new major amputations are performed annually in the United States [1] while as at 1991, there are 132 amputees per 1000 of the total population, in the United Kingdom [2]. Data from Nigeria is sparse [3] but Onuba et al [4] reported that $0.38 \%$ of all orthopaedic operations were amputations while Thanni [5] reported 1.6 per 100,000 as the estimated prevalence of extremity amputation in Nigeria. Amputation might be required for several reasons. Peripheral vascular disease (PVD) predominates and it is seen in about $64 \%$ of cases, diabetes $20 \%$, trauma $7 \%$, malignancy $3 \%$, infection $2 \%$, and congenital deformities taking about $4 \%$ [6]. From the above, peripheral vascular disease and diabetes gangrene put together $-84 \%$ - accounts for majority of the lower limb amputation. Patients with these diseases usually also have many other associated medical problem, such as, atherosclerosis of cerebral vessels causing possible hemiplegia and diminish mental ability, cardiac involvement, low exercise tolerance, reduced vision, poor respiratory function and possibly osteoarthritis [7].

Amputation causes physical, psychological and emotional dysfunction [8], necessitating caregiver's support for rehabilitation and general care. Many studies associated amputation care with psychological burden [9], financial burden [10], physical and mental stress on family and social relationship [11]. Highlighting the heavy burden borne by caregivers and drawing attention to their often unmet needs may help to raise awareness within the health care community of the impact of amputation on patient's family. They may also provide a useful resource for defining structured intervention geared at assessing, preventing or managing problems related to stressful caregiving situations across the care continuum [12].

More, so studies have focused on caregivers of patients affected by Alzheimer's disease and dementia [13], stroke [14] and Parkinson's disease $[12,15]$ but few studies have analysed the factors associated with caregiver burden in individuals with amputation [11]. Study on caregiver burden in children and adolescents with mental health problems was carried out in Nigeria by Dada, et al. [16]. Another study on health and wellbeing of caregivers of children with cerebral palsy was carried out by Raina, et al. [17]. Also, the quality of life of Nigerians with amputation has been studied by Babatunde, et al., [2] but, there is a dearth of studies in Nigeria on the burden of caregivers of patients with amputation. The aim of this study, therefore, is to assess the caregiver burden in patients with either above elbow, below elbow, above knee or below knee amputation. The association between caregiver burden and selected factors will also be determined.

\section{Materials and Methods}

\section{Respondents}

Caregivers caring for individuals with amputation were recruited for the study from the following selected hospitals: Obafemi Awolowo University Teaching Hospitals Complex Ile-Ife, Seventh Day Adventist Hospital, Ile-Ife, National Orthopaedic Hospital Igbogbi, Lagos, Nigerian Army Reference Hospital Yaba, Lagos.

\section{Inclusion criteria}

Inclusion criteria were caregivers who are: caring for the
Phys Med Rehabil Int - Volume 4 Issue 4 - 2017 ISSN : 2471-0377 | www.austinpublishing group.com Ojoawo et al. (C) All rights are reserved 
individuals with amputation for at least two weeks; family members of the individuals with amputation, caring for individuals who had either above elbow, below elbow, above knee or below knee amputation and are still on admission, able to speak or understand the English and/or Yoruba languages and who gave consent to participate in the survey.

\section{Exclusion criteria}

Caregivers who: are unable to speak or understand the English and/or Yoruba Languages; were also caring for other individuals with similar condition or chronic medical, neurological, orthopaedic conditions but not amputation are caring for partial hand or foot amputation and/or amputation of one or more digits.

\section{Sampling technique:}

Respondents were recruited using non-probability purposive sampling technique.

\section{Sample size calculation [18]:}

The sample size was calculated using the formula:

\section{$\mathrm{N}=4(\mathrm{Z})^{2} \mathrm{p}(1-\mathrm{p}) / \mathrm{D}^{2}$}

Where $\mathrm{p}=$ pre-study estimate of proportion, $\mathrm{N}=$ sample size of the single study group, $\mathrm{Z}=$ standard normal deviation $(1.96) . \mathrm{D}=$ total width of expected confidence interval (0.2).

$$
\mathrm{N}=4(1.96)^{2} \times 0.2(1-0.2)=61.5 / 0.2^{2}
$$

The sample size will be rounded up to 70 to accommodate for non-response.

\section{Instruments}

The instruments used in this study included a self-administered questionnaire, Zarit Burden Interview (ZBI) [19] which consists of two sections. The first section (Section A) was used to collect sociodemographic information such as: age, sex, level of education and occupation of both amputee and caregiver, length of hospital stay, amputation type, side of affectation and cause of amputation. The second section (Section B) was adopted from the caregiver strain interview- Zarit Burden Interview is a 22 -item instrument with 5 domains which consist of employment, financial, physical, social and time domains. Respondents rated the frequency to which items applied to them on a 5-point scale; ranging from 'never' to 'near always'. Scores were assigned to each item with the lowest score being 22 and the highest score being 105.

\section{Procedure}

Ethical approval was obtained from the Health Research Ethics Committee of the Institute of Public Health of Obafemi Awolowo University Ile-Ife. The procedure was explained to the respondent prior to assessment and informed consent was obtained before data collection. Participants who met the criteria for inclusion in this study were asked to fill the Zarit Burden Interview questionnaire.

\section{Data analysis}

Data was analysed using SPSS version 17. Descriptive statistics of mean, standard deviation, frequency and percentage was used to summarize the data that will be obtained in the study. Analysis of variance was used to compare the care givers burden among different level of amputation. Independent -t-test was used to examine the difference between caregivers burden of male and female amputees.
Table 1: Frequency distribution of sociodemographic variables of caregivers and amputees

\begin{tabular}{|c|c|c|}
\hline Variable & Care givers $(\mathrm{n} \%)$ & Amputees $(\mathrm{n} \%)$ \\
\hline Mex & & \\
\hline Female & $21(31.8)$ & $18(72.7)$ \\
\hline Level of Education & $45(68.2)$ & $3(4.5)$ \\
\hline No Education & $1(1.5)$ & $3(4.5)$ \\
\hline Primary Education & $2(3.0)$ & $17(25.8)$ \\
\hline Secondary Education & $15(22.7)$ & $43(65.2)$ \\
\hline Tertiary Education & $48(72.7)$ & $17(25.8)$ \\
\hline Occupation & & $10(15.2)$ \\
\hline Civil servants & $14(21.2)$ & $16(24.2)$ \\
\hline Traders & $24(36.4)$ & $8(12.1)$ \\
\hline Military & $0(0)$ & $3(4.5)$ \\
\hline Retirees & $0(0)$ & $12(18.2)$ \\
\hline Students & $17(25.7)$ & \\
\hline Others & $116.7)$ & \\
\hline
\end{tabular}

Table 2: Mean and Standard deviation of age and caregivers burden of amputee.

\begin{tabular}{|c|c|c|c|}
\hline Variables & Minimum & Maximum & Mean \pm SD \\
\hline Age Caregivers /yrs & 18 & 65 & $36.6 \pm 13.0$ \\
\hline Age of amputees/yrs & 25 & 71 & $47.5 \pm 13.8$ \\
\hline Caregivers burden & 39 & 84 & $55.56 \pm 9.82$ \\
\hline
\end{tabular}

\section{Results}

Presented in Table 1 is the frequency distribution and sociodemographic factor of caregivers and amputees. There were 45 female caregivers, and 48 male amputees; 48 (72.7\%) caregivers had tertiary education and 43 (65.3\%) amputees had tertiary education. Civil servants form the largest percentage among the amputees (25.8\%) and business.

The mean age of the caregivers and amputees were $36.6+13.0$ years and $47.5+13.8$ years respectively and the mean care givers burden was $55.56+9.82$ as shown in Table 2 .

Below knee amputation for the largest $(42,63.6 \%)$ amputation type in the facilities assessed, left side has the highest percentage (33, $50 \%$ ) and road traffic accident caused $45.5 \%$ amputation.

\section{Comparison between male and female amputees care givers burden}

Table 3 revealed that female caregiver burden is significantly higher $(\mathrm{t}=2.842, \mathrm{p}<0.01)$ than that of male burden.

\section{Comparison among the caregivers burden among different level of amputation}

The result showed that there was a significant difference $(\mathrm{F}=4.80$, $\mathrm{p}<0.01$ ) among care givers burden of above elbow, above knee and below elbow and below knee with above knee having the highest burden (Table 4, 5). 
Table 3: Clinical characteristics (type of amputation, side of amputation and cause of amputation) of amputees.

\begin{tabular}{|c|c|c|}
\hline Variable & Frequency (n) & Percentage \\
\hline \multicolumn{3}{|l|}{ Amputation Type } \\
\hline \multicolumn{3}{|l|}{ Lower Limb } \\
\hline Above Knee & 14 & 21.2 \\
\hline Below Knee & 42 & 63.6 \\
\hline Total & 66 & 84.8 \\
\hline \multicolumn{3}{|l|}{ Upper Limb } \\
\hline Above Elbow & 2 & 3.0 \\
\hline Below Elbow & 8 & 12.2 \\
\hline Total & 10 & 15.2 \\
\hline \multicolumn{3}{|l|}{ Amputation Side } \\
\hline Both sides & 5 & 7.6 \\
\hline Left & 33 & 50.0 \\
\hline Right & 28 & 42.4 \\
\hline \multicolumn{3}{|l|}{ Cause of Amputation } \\
\hline Diabetes mellitus & 25 & 37.9 \\
\hline Road Traffic Accident & 30 & 45.5 \\
\hline War & 2 & 3.0 \\
\hline Violence & 9 & 13.6 \\
\hline
\end{tabular}

Table 4: Independent t-test showing the results of the comparison of caregiver burden among male and female amputees.

\begin{tabular}{|c|c|c|c|}
\hline Variables & Mean + SD & $t$ & $\mathrm{P}$ \\
\hline Male & $54.25 \pm 9.27$ & 2.842 & 0.05 \\
\hline Female & $59.24 \pm 10.53$ & & \\
\hline
\end{tabular}

Table 5: Results of the comparison of caregiver burden among different levels of amputation using ANOVA.

\begin{tabular}{|c|c|c|c|}
\hline Variables & Mean + SD & F & P \\
\hline Below Knee & $52.38 \pm 8.29^{\mathrm{a}}$ & & \\
\hline Above Knee & $63.43 \pm 9.51^{\mathrm{b}}$ & \multirow{2}{*}{4.80} & \multirow{2}{*}{$0.005^{\star}$} \\
\hline Below Elbow & $60.13 \pm 10.48^{\mathrm{c}}$ & & \\
\hline Above Elbow & $52.50 \pm 6.37^{\mathrm{a}}$ & & \\
\hline
\end{tabular}

Key: *Significant at $P<0.01$. Superscript letters $(a, b, c)$ within the tabled mean mode with the same superscript letters indicate no significant difference between means. Mean mode with different superscript letters indicate significant difference.

\section{Discussion}

The study assessed the caregiver burden in individuals with amputation in selected hospitals in south western Nigeria.

The results of the study showed that more males than females underwent amputation. The male to female ratio was 3:1. This supports findings from previous studies that lower limb amputations are more common among males than females [20-22]. The difference in proportion may be due to the fact that men tend to work with heavy machinery and participate in high risk activities than women. In addition, males are the bread-winners of most families, therefore, they engage in more physical exertions, with increased exposure to risks of injuries that may necessitate ablative surgery.

The findings from this study also showed that below knee amputation was the most commonly performed of all major limb amputations. It accounted for $84.6 \%$ of all the amputation done in the studied facilities. Our finding was in support of the study of Davies et al [23], in which they found a lower limb amputation of $85.0 \%$ in their study. Researchers also found that lower limb amputation was common more than upper limb amputation $[3,21,24,25]$. Below-knee amputation is considered a better option than above-knee, whenever possible, because it preserves the knee with its proprioceptive function and reduces energy expenditure at ambulation [26].

The sudy also observed that larger percentage of amputations resulted from road traffic acidents (RTA). These findings agreed with previous studies by Babatunde, et al., [2] and Edomwonyi \& Onuminya, [3] where trauma was the leading cause of amputation. Reports from researches asserted that $50 \%$ of all amputation in Nigeria is due to traumal and injury as a result of road traffic acident $[21,27]$. The findings in our study may not be unconnected to the challenges facing the nation and individuals. One of the major national challenges is poor maintanance of roads both the highways and other roads which cumultated to pot holes and small ditches on the road creating a menance for road users. In addition to this the country is experiencing a period of economic resession which makes it difficult to buy new tyres to the vehicle. Majority of road users both personal cars and commercials have resulted into cheap and possibly expired tyres which predisposes such vehicle to accident. More importantly, many road user have nonchalant attitudes to safety rules and regulations while driving.

Similarly, diabetis mellitus was found to be one of the leading causes of amputaion after RTA. The report of this study run in line with a study by Okenwa, et al., [26] where diabetes mellitus and vascular gangrene were reported as the most common indication for amputation. Peripheral sensory neuropathy which is one of the complication of diabetes mellitus has been reported to be a major contributor of foot amputations and increases risk of foot amputations in patients with diabetes mellitus [28].

The mean age of the amputees $(47.5+13.8$ years $)$ in this study was found to be at productive age. This agrees with the findings of Onuba \& Udoidiok [2] and Unegbu \& Dim, [29]. The facts remains that younger people are involved in a life risking ventures, more aggressive and ambitious which predispose them to RTA found in this study to be responsible for most ammputations.

Our findings revealed that civil servant and military formed the highest occupation among the amputees. These categories of occupations were more involved in travelling across the country and across the states thereby predisposing them to road traffic acident. In addition there is generally low physical activity level with respect to civil servants; the situation that can lead to abnormal accumulation of fat which may evetually resulted in diabetes melletus. In as much there is high prepoderance of male among the amputees, it is expected that their spouse or children needs to be in the hospitals taking care of them, accounting for the reason for more students and females more among the caregivers. This is in agreement with a similar study by the Association on Aging [30] which reported that most caregivers were females and many of them are also caring for other family members.

Most caregivers in this study were in their younger age category. In addition, highest percentage of caregivers had tertiary education. 
This is in agreement with the findings of Akosile et al, [31] where $56 \%$ and $35 \%$ of the caregivers were young adults and middle-aged respectively. This may be because younger age group have more time to take care of their loved ones during periods of illness unlike most adults who are very busy with their work and family. More so, the rate of unemployment in the country is very high, therefore higher institution graduates who had now here to go are useful in taking care of the family members in health challenges including amputees.

The results show that the care giver burden of female amputees were more than that of male amputees. The finding of this study with respect to female care givers burden may be expected, because of the peculiarity of women with respect to dressing, menstrual circle and make ups, which were not part of men ways of life. Care givers of female amputees may not be surprising to be found higher. Caregivers caring for individuals with above knee amputations experienced the highest level of burden compared with caregivers caring for individuals with other levels of amputation. The absence of knee joint in the below knee amputation makes is more difficult for the amputee to learn the usage of prosthesis quickly which increases the burden of the patient. Turney et al. [32] also reported that there was a significant difference in the environment domain scores of individuals with different levels of lower limb amputation and that the only predictor of environmental adaptation in those with lower limb amputation is the level of amputation. The limitations of the study are that the questionnaire employed is a self reported, and the post- prosthetic stages of the amputees were not assessed during the study.

It can be concluded from the study that burden of mean care given to an average amputee may be estimate as just above average but above knee and female amputee may require more care.

\section{References}

1. Walter S, Burgess E, Romemo Rand, Zettle, J. The Management of Lower Extremity Amputations, New York, U.S.A: Government Printing Press. 2003.

2. Adegoke BOA, Kehinde AO, Akosile CO and Oyeyemi LO. Quality of Life of Nigerians with Unilateral Lower Limb Amputation. Disability, CBR \& Inclusive Development. 2013: 23; 76-89.

3. Edomwonyi E and Onuminya JE. An Update on Major Lower Limb Amputation in Nigeria. IOSR Journal of Dental and Medical Sciences. 2014; 13; 90-97.

4. Onuba $\mathrm{O}$ and Udoidiok $\mathrm{E}$. The Scope of amputation in developing Countries. Postgraduate Doctor. 1989; 11: 118-121.

5. Thanni $L$ and Tade A. Extremity amputation in Nigeria-A Review of Indications and Mortality. Surgeon. 2007; 5; 213-217.

6. Dillingham T, Pezzin L and Mackenzie E. Limb Amputation and Limb Deficiency: Epidemiology and Recent Trends. Southern Medical Journal. 2002; 95: 875-883.

7. Van der Van C. Amputation. In: Patricia Downie and Susan Boardman (Eds), ed. Cash's Textbook of General Medical and Surgical Conditions for Physiotherapist. $2^{\text {nd }}$ Edition ed. India: Jaypee Brothers Medical Publishers. 1993: 265-292

8. Dougherty $\mathrm{P}, \mathrm{McF}$ arland L, Smith $\mathrm{D}$ and ReiberG. Bilateral Transfemoral/ Transtibial Amputations due to Battle Injuries: A Comparison or Vietnam Veterans with Iraq and Afghanistan Service-members. Clin Orthop Relat Res. 2014; 472: 3010-3016.

9. Ramachandran V, Rogers-Ramachandran D and Cobb S. Touching the Phantom Limbs. Ann Rheum Dis. 2011; 70; 1775-1781.

10. Lim J and Zebrack B. Caring for family members with chronic physical illness: a critical review of caregiver literature. Health Qual Life Outcomes. 2004: 2; 50 .
11. Moradi A, Mohammad HE and Mohamad RS. Quality of Life of Caregiver Spouses of Veterans with Bilateral Lower Extremity Amputations. Trauma. 2015; 20: $26-30$

12. Bartolo M, De Luca D, Serrao M, Sinforrami E, Zucchella C, Sandrini G Caregiver Burden and Needs in Community Neurorehabilitation. J Rehabil Med. 2010; 42: 818-822.

13. Etters, L, Goodall D and Harrison B. Caregiver Burden Among Dementia Patient Caregivers: A Review of Literature. J Am Cad Nurse Pract. 2008; 423-428.

14. Smith J Foster A Young J. Cochrane review: information provision for stroke patients and their caregivers. Clin Rehabil. 2009; 23: 195-206.

15. Martinez-Martin P, Arroyo S, Rojo-Abuin JM, Rodriguez-Blazquez C, Frades B, Cuesta JP. Longitudinal Parkinson's disease study, Burden, percieved health status and mood among caregivers of Parkinson's disease patinet. Mov Disord. 2008; 23: 1673-1680.

16. Dada M, Okewole N, Ogun O \& Bello-Mojeed M. Factors associated with caregiver burden in a Child and Adolescent Psychiatric Facility in Lagos, Nigeria: A Descriptive Cross Sectional Study. BMC Pediatr. 2011; 11: 110.

17. Raina P, O'Donnell M, Rosenbaum P, Brehaut J, Walter S, Russell D, et al The Health and Well-being of Caregiver of Children with Cerebral Palsy. J Am Acad Pardiatr. 2005; 115: 626-636.

18. Eng J. Sample size calculation: How many individuals should be studied? Radiology. 2003; 227: 309-313.

19. Zarit SH, Orr NK and Zarit JM. The hidden victims of Alzheimer's disease: Families under stress, New York: New York University Press. 1985.

20. Thomson A, Alison S. and Joan P. Physiotherapy for Amputees. In: P. B Stuart, ed. Tidy's Physiotherapy. Manchester: Butterworth-heinemann. 2002; 505-512.

21. Ogunlade S, Alonge I and Omololu A. Major limb Amputation in Ibadan. Afri. J. Med. Sci. 2002; 31: 333-336.

22. Yakubu, A., Muhammed, I. \& Mabogunje, O. Limb Anputations in Children in Zaria, Nigeria. Ann. Tro. Paediatric. 1995; 15: 163-165.

23. Davis WA, Kingston DR, Fyling CP, Gena F. Amputation prevention in an independently reviewed at-risk population. American Journal of Surgery. 2003; 160: 454-460.

24. Dada Aand Awoyomi B. Is the trend of amputation in Nigeria Changing? A review of 51 Consecutive Cases Seen at FMC Ebutte - metta, Lagos, Nigeria. Niger J. Med. 2010; 51: 167-169.

25. Onuminya JE, Obekpa PO, Ihezue HC, Ukegbu ND, Onabowale BO. Majo amputations in Nigeria: a plea to educate traditional bone setters. Tropical Doctor. 2000: 133-135.

26. Okenwa WO, Oeyichukwu G and Cnevo A. Amputation of the limbs: 10years experience at Enugu State University. Orient Journal of Medicine. 2015; 27 : 40-45.

27. Olaogun MOB, Lamidi ER. Appraisal of lower limb amputations and some rehabilitation problems of amputees. Journal of the Nigeria Society of Physiotherapy. 2005; 15: 1-7.

28. Vinik Al, Mehrabyan A. Diabetic neuropathies. Med Clin North Am. 2004; 88 : 947-999.

29. Unegbu Mand Dim E. Safer Amputations: A review of 158 cases. Nigerian Journal of Surgical Sciences. 2007; 17: 25-32.

30. Association of Aging. Administration on Aging. 2007.

31. Akosile CO, Okoye EC, Adegoke BOA, Mbada CE and Maruf FA. Burden, Health and Quality of Life of Nigerian Stroke Caregivers. Health Care Current Reviews. 2013; 1: 1-5.

32. Turney B, Kent S, Walkers R and Loftus I. Amputations: No longer the end of the road. Journal of Royal College of Surgeons of Edinburgh. 2001; 46: 271-273. 